\title{
A PESQUISA NARRATIVA NA ANÁLISE DO DESENVOLVIMENTO PROFISSIONAL DO FORMADOR DE PROFESSORES DE MATEMÁTICA
}

FLÁVIA CRISTINA FIGUEIREDO COURA

Universidade Federal de São João del Rei

RESUMO Neste artigo, o objetivo é apresentar e analisar a narrativa de experiências de desenvolvimento profissional de uma formadora de professores de Matemática. O conceito de desenvolvimento profissional utilizado é apresentado, inclusive quando o docente em questão é o formador de professores. A pesquisa narrativa foi o caminho metodológico utilizado para produzir os textos de campo e para transformá-los em texto de pesquisa, por meio da análise narrativa. A interpretação da história de vida da formadora possibilitou identificar experiências que influenciaram seu desenvolvimento profissional, que representam vias de transformação pessoal, contribuindo para a constituição de uma profissionalidade. Nesse percurso, a pesquisa narrativa, por ter permitido representar um conjunto de dimensões da experiência que a investigação formal não contempla, tornou possivel atingir o caráter subjetivo do desenvolvimento profissional e o processo por meio do qual a pessoa se desenvolve.

Palavras-chave: Pesquisa narrativa. Desenvolvimento profissional. Formador de professores de matemática.

\section{ABSTRACT THE NARRATIVE INQUIRY TO ANALYZE PROFESSIONAL DEVELOPMENT OF MATHEMATICS TEACHER EDUCATOR}

This article aims to present and analyze the narrative of the professional development experiences of a Mathematics teacher educator. The concept of professional development used is presented, taking into consideration that the teacher in question is a teacher educator. Narrative inquiry was the methodological framework used to produce the field texts and to transform them in research texts, through narrative analysis. Interpreting the educator's life history has allowed for the identification of experiences which influenced her professional development, which represent personal transformation possibilities, thus contributing to the construction of a professionality. Therefore, by enabling the representation of a set of facets of the experience 
which traditional inquiry does not encompass, narrative inquiry made it possible to reach the subjective aspect of professional development and the process through which people develop themselves.

Keywords: Narrative inquiry. Professional development. Mathematics teacher educators.

\section{RESUMEN LA INVESTIGACIÓN NARRATIVA PARA ANALIZAR DESARROLLO PROFESIONAL DEL FORMADOR DE PROFESORES DE MATEMÁTICA}

En este artículo, el objetivo es presentar y analizar la narrativa de experiencias de desarrollo profesional de una formadora de profesores de Matemáticas. El concepto de desarrollo profesional utilizado es presentado, incluso cuando el docente en cuestión es el formador de profesores. La Investigación Narrativa fue el camino metodológico utilizado para producir los textos de campo y para transformarlos en texto de investigación, por medio del análisis narrativo. La interpretación de la historia de vida de la formadora posibilitó identificar experiencias que influenciaron su desarrollo profesional, que representan vías de transformación personal, contribuyendo a la constitución de una profesionalidad. En este recorrido, la investigación narrativa, por haber permitido representar un conjunto de dimensiones de la experiencia que la investigación formal no contempla, hizo posible alcanzar el carácter subjetivo del desarrollo profesional y el proceso por medio del cual la persona se desarrolla.

Palabras clave: Investigación Narrativa. Desarrollo profesional. Formador de profesores de Matemáticas.

\section{Introdução}

No Brasil, o termo "formador de professores de Matemática" usualmente faz referência ao docente do Ensino Superior que atua na formação de professores de Matemática. Embora seja uma figura importante na formação docente, na medida em que, durante suas aulas, realiza um trabalho muito parecido com o que o licenciando presenciou quando aluno da Escola Básica e com o que pode realizar, se for lecionar, há uma lacuna nos resultados de pesquisa quanto aos seus processos forma-

1 ANDRÉ et al, 2012; COURA, 2013; HOBOLD; MENSLIN, 2012; MARCELO GARCÍA, 1999b; PASSOS; SILVA; FERREIRA, 2013; VAILLANT, 2003. ção, ${ }^{2}$ inclusive quando se trata do formador de professores de Matemática (COURA; PASSOS, 2017; FIORENTINI, 2004). Diante da importância e da necessidade de estudos que focalizem o formador de professores, ${ }^{3}$ em Coura (2018), voltamos ${ }^{4} \mathrm{o}$ olhar para o desenvolvimento

2 ANDRÉ et al, 2010; FIORENTINI et al, 2002; KELCHTERMANS; SMITH; VANDERLINDE, 2017; MARCELO GARCÍA, 1999a; MIZUKAMI, 2010; VAILLANT, 2003; VANASSCHE; KELCHTERMANS, 2014.

3 ALTET; PAQUAY; PERRENOUD, 2003; SANTOS, 2005; ZEICHNER, 2005.

4 Neste texto, em muitos momentos, deixo minha individualidade, para assumir, com minha orientadora de doutorado, com os pesquisadores com quem dialogo e com os formadores entrevistados, o relato na primeira pessoa do plural. 
profissional de formadores ${ }^{5}$ de professores de Matemática que foram caracterizados como investigadores da docência.

Nessa pesquisa, em que interpretamos experiências de desenvolvimento profissional $^{6}$ dessas formadoras, a narrativa foi a via utilizada para ter acesso ao que cada uma dessas seis docentes pensa, vive e pensa sobre o que viveu. A pesquisa narrativa, nos termos defendidos por Clandinin e Connelly (2011), foi se constituindo como um caminho a fim de recontar essas histórias, para que, além de compreensão, permitam desenvolvimento e mudança, para que nos afetem de um modo existencial (CONTRERAS DOMINGO, 2016).

Neste artigo, analisamos a narrativa de experiências de desenvolvimento profissional de uma formadora de professores de Matemática. Para isso, inicialmente, apresentamos o conceito de desenvolvimento profissional que utilizamos e como o entendemos quando o docente em questão é o formador de professores. Descrevemos a pesquisa narrativa como caminho metodológico e o processo de análise narrativa utilizado. Em seguida, narramos as experiências de desenvolvimento profissional dessa formadora de professores de Matemática. Ao final, tecemos considerações sobre as experiências de desenvolvimento profissional que a narrativa apresentada nos dá a ver e sobre as singularidades e potencialidades da pesquisa narrativa para investigações sobre 0 desenvolvimento profissional.

5 Como a questão do gênero das participantes não foi considerada, embora todas sejam formadoras de professores, mantivemos a palavra formadores no título e no objetivo, para fazer referência a um grupo de profissionais que inclui formadores dos gêneros feminino e masculino.

6 As experiências de desenvolvimento profissional representam vias de transformação pessoal (LARROSA BONDÍA, 2002), que se caracterizam pela continuidade - toda experiência vive e se prolonga em experiências que se sucedem - e pela interação, quando as condições objetivas estão em equilíbrio com o que ocorre dentro de quem passa pela experiência (DEWEY, 1971).

\section{O desenvolvimento profissional do formador de professores}

Tomando como pressuposto que os processos de aprender a ensinar, de aprender a ser professor, são lentos e contínuos, iniciando-se antes do ingresso na formação inicial e prolongando-se por toda a vida (MIZUKAMI, 2006), é razoável considerar que o trabalho que o formador exerce na licenciatura, além de ensinar Cálculo, Álgebra ou Didática, revela um modo de ser professor (FIORENTINI, 2004; FIORENTI$\mathrm{NI}$; OLIVEIRA, 2013). Por outro lado, o próprio formador é um professor que também se forma no exercício da profissão, pois precisa mobilizar seus conhecimentos para empreender práticas que atendam as demandas do seu âmbito de atuação profissional (COSTA; PASSOS, 2009; DAL-FORNO; REALI, 2009). O contexto de trabaIho configura-se como um fator que influencia sua prática, seus saberes, sua formação e a de seus alunos (ANDRÉ et al, 2010; PASSOS, 2007). Desse modo, o formador mantém uma relação dupla com a formação de professores, como agente de sua própria formação e de seus alunos, futuros professores de Matemática.

Perante a importância da atuação profissional para a formação do formador de professores de Matemática, relacionamos os conceitos de desenvolvimento profissional (GUIMARÃES, 2005; MARCELO GARCÍA, 1999b; MINGORANCE DÍAZ, 2001; e PASSOS et al, 2006) e de conhecimento da prática (COCHRAN-SMITH; LYTLE, 1999), o que nos levou a assumir que, para além do processo de produção e de racionalização de conhecimentos e habilidades necessários a um exercício profissional com autonomia, para decidir e controlar os processos sob sua responsabilidade, ou seja, para além da constituição de uma profissionalidade, o desenvolvimento profissional é contínuo, singular, multidimensional e contextual (espaço e tempo), envolvendo transformações 
na pessoa que o professor é e depende da investigação da prática que ele realiza. É a esse processo que nos referimos quando recorremos, neste texto, ao termo "desenvolvimento profissional".

Voltando o olhar para estudos que interpelam o desenvolvimento profissional do formador de professores, encontramos perspectivas para entender o formador como pesquisador (COCHRAN-SMITH, 2005), a identidade profissional de formador-investigador (FIORENTINI, 2004), a postura que Zeichner (2005) defende para a constituição de uma expertise do formador de professores e a via para uma profissionalidade, indicada nos estudos que compõem a obra de Altet, Paquay e Perrenoud (2003). Esses pesquisadores, embora sem usar explicitamente essas palavras, também defendem a investigação da prática como um componente essencial ao desenvolvimento profissional do formador de professores.

Consideramos que o formador de professores de Matemática se desenvolve profissionalmente por meio de um processo contínuo, multidimensional, autônomo e singular, desenvolvido em contextos e momentos diversificados, que depende da relação que ele estabelece entre investigação e docência e implica uma transformação pessoal.

\section{A pesquisa narrativa como caminho para compreender o desenvolvimento profissional}

Considerar o desenvolvimento profissional do formador tal como enunciamos, trouxe a necessidade de novos encaminhamentos para a investigação, tal como alerta Guimarães (2005). Assumir a intencionalidade e a importância da agência do formador, tomá-lo como sujeito do desenvolvimento, demanda concentrar nele o foco da pesquisa. Com isso, para compreender seu processo de desenvolvimento, é preciso integrar a sua biografia à investigação. Outra consequência de reconhecer a importância da trajetória pessoal de vida e de formação do formador, em seu desenvolvimento, é a necessidade de abordar esse processo diacronicamente, levando em consideração a história da pessoa que se desenvolve, as relações que estabelece com o que viveu, o hoje e suas expectativas futuras. Essa visão reforça o caráter de continuidade do desenvolvimento profissional e impõe que a investigação considere o tempo como um eixo sobre o qual esse desenvolvimento acontece, que abrange a sucessão dos acontecimentos da sua vida, a sua história.

Além do tempo ao longo de sua trajetória, o tempo em que oformador se encontra em determinado lugar, de vida, de trabalho, compõe o contexto no qual ele se desenvolve. Tomar o contexto como um fator que pode determinar o desenvolvimento cognitivo e, desse modo, o desenvolvimento profissional (GUIMARÃES, 2005), implica considerar que o contexto no qual o formador se insere não é somente o local onde ele vive e trabalha, mas é o local onde vive, o local onde trabalha, ao longo de um determinado período de tempo. É preciso considerar que o desenvolvimento profissional é situado em um contexto que tem duas dimensões: espacial e temporal.

Em suma, para buscar uma compreensão a respeito do desenvolvimento profissional, é necessário ter em conta que se trata de "um processo que decorre ao longo de toda a carreira do professor e no qual, através das suas experiências, refletindo e interagindo com o mundo, o professor, permanecendo ele próprio, forma-se e transforma-se, globalmente" (GUIMARÃES, 2005, p. 153).

Em razão disso, a narrativa se constituiu como caminho para elaborar, expressar e compreender as experiências de desenvolvimento profissional de formadores de professores de Matemática, pois, assim como defendem Clan- 
dinin e Connelly (2011), com os pressupostos do pensamento narrativo, podemos localizar os acontecimentos, as experiências no tempo, não como algo que aconteceu naquele momento, mas como uma expressão de algo acontecendo ao longo do tempo. Conseguimos considerar também que as pessoas, em qualquer ponto do tempo, estão em processo de mudança pessoal e que o contexto está sempre presente, sendo necessário para dar sentido a qualquer pessoa, evento ou coisa.

Procuramos narrar as experiências de desenvolvimento profissional das formadoras no espaço tridimensional da pesquisa narrativa e também, como defendem Clandinin e Connelly (2011), compreendê-las, abordando a temporalidade dos acontecimentos, suas condições pessoais e sociais e o contexto (tempo e espaço) em que ocorreram. Foram realizadas entrevistas dialógicas em profundidade com caráter biográfico-narrativo (DOMINGO SEGOVIA, 2014) com as seis participantes da pesquisa de doutorado (COURA, 2018), formadoras de professores de Matemática, que trabalham em seis instituições de ensino superior situadas em quatro estados brasileiros (Espírito Santo, Minas Gerais, Paraná e São Paulo). A intenção foi conhecer a trajetória das formadoras a partir do ponto vista de cada uma: o interesse estava em ouvir a história de vida e de formação, contada por quem a viveu.

Seguindo os pressupostos da pesquisa narrativa (CLANDININ; CONNELLY, 2011), a partir das entrevistas com as formadoras, foram produzidos três textos de campo ${ }^{7}$ - o mapeamento

7 Assim como Clandinin e Connelly (2011, p. 133), usamos o termo "textos de campo" para designar os tipos de registro normalmente chamados de "dados", que esses autores assim denominam "porque são criados, não são encontrados e nem descobertos, pelos participantes e pesquisadores, com o objetivo de representar aspectos da experiência de campo". Os textos de campo são "registros de interpretações do que experimentamos do mundo existencial, e mesmo ao compormos textos de campo falamos sobre nossas experiências, sentimentos, dúvidas, incertezas, reações, histórias lembradas e assim por diante". (Clan- da trajetória de cada formadora, a transcrição da entrevista e as notas de campo - que, sob minha ${ }^{8}$ interpretação, ${ }^{9}$ resultaram nos textos de pesquisa, ou seja, nas narrativas de experiências de desenvolvimento profissional das participantes. É esse processo analítico-interpretativo que descreveremos a seguir.

\section{O processo de análise narrativa-}

Clandinin e Connelly (2011, p. 176) afirmam que a transição dos textos de campo para os textos de pesquisa é um movimento vivenciado pelo pesquisador narrativo pois, para esses autores, "os textos de campo precisam ser reconstruídos para se tornarem textos de pesquisa". nesse sentido que usamos o termo "transição", para fazer referência ao processo analítico-interpretativo de questionamento repetitivo a respeito do sentido e da relevância social dos textos de campo para tematizá-los narrativamente.

Além de texto de pesquisa, a narrativa constituiu-se como método para gerar conhecimento sobre as experiências das formadoras. Nas seis narrativas apresentadas em Coura (2018), buscando um conhecimento narrativo (BOLIVAR; DOMINGO; FERNÁNDEZ, 2001) das experiências de desenvolvimento profissional das participantes, centramos foco mais nas intenções que identificamos e em seus significados do que nos acontecimentos ou fatos objetivamente descritos; procuramos mais pela coerência do que pela lógica, pela compreensão no lugar da previsão e do controle.

dinin; Connelly, 2011, p. 126)

8 Ao longo do texto, recorro à primeira pessoa do singular, quando me refiro às minhas vivências, opiniões e observações. Uso a primeira pessoa do plural, o "nós", quando me coloco junto a outros, sejam eles minha orientadora, os autores a que faço referência, ao longo do texto, ou as formadoras que participaram do estudo.

9 Em Coura e Passos (2018), apresentamos as etapas de produção dos dados, realizada a partir de entrevista dialógica em profundidade, com caráter biográficonarrativo e de composição dos textos de campo. 
Com esses textos produzidos a partir dos relatos das formadoras, na entrevista, procuramos compreender por que elas dizem o que dizem, o que é diferente de analisar a veracidade do que foi dito. Busquei, ao escrever a respectiva narrativa, estabelecer um fluxo diacrônico, uma cronografia de elementos importantes (DOMINGO SEGOVIA, 2014) da história de vida de cada uma. Pautei-me pela intenção de mostrar os elementos singulares que compõem cada história de vida, sem aspirar à generalização.

Procedemos ao que Bolivar, Domingo e Fernández (2001) chamam de análise narrativa propriamente dita, que gera a narração de uma trama ou argumento mediante um relato narrativo. Não se buscam elementos comuns, mas sim elementos singulares que configuram a história (GARNICA, 2009). 0 processo de uma análise narrativa, nessa perspectiva, é, então, sintetizar os dados em um conjunto que almeja ser coerente, em lugar de separá-los por categoria. O resultado dessa integração narrativa é uma sequência temporal, em que procuramos constituir os primeiros elementos para identificar que experiências de desenvolvimento profissional os formadores de professores de Matemática vivenciam em sua trajetória de vida e de formação.

Tendo este objetivo em vista, contamos parte da história de vida de uma formadora de professores de Matemática, segundo os segmentos narrativos que identificamos em sua fala. Na narrativa apresentada a seguir, procuramos preservar sua voz e com ela estabelecer alguns diálogos, utilizando para isso sua própria produção acadêmica, um registro de sua fala, proferida em tempos, lugares e interações diferentes daqueles da realização da entrevista..$^{10}$ Com isso, tentamos compor um tex-

10 Em vista desse uso da produção bibliográfica da participante, na narrativa, foi preciso fazer-lhe referência de dois modos: ora pelo primeiro nome, quando me refiro ao que me disse na entrevista, que registro em to olhando retrospectiva e prospectivamente (continuidade), introspectiva e extrospectivamente (interação), situando a experiência dentro de um lugar (situação), procurando criar um espaço tridimensional para a investigação, como recomendam Clandinin e Connelly (2011).

\section{Narrativa de experiências de desenvolvimento profissional de Maria Teresa Menezes Freitas}

Maria Teresa concluiu a Licenciatura Plena em Matemática em 1974, na Universidade Federal de Uberlândia (UFU), instituição na qual é professora vinculada ao Departamento de Matemática desde 1980, e onde estudou em um curso de Especialização em Matemática Superior, de 1980 a 1982, e no Mestrado em Educação, concluído no ano 2000, quando apresentou dissertação sobre o estágio curricular em Matemática da UFU, na perspectiva de extensão universitária, orientada pela professora Marilúcia de Menezes Rodrigues. Fez o doutorado de 2002 a 2006, na Faculdade de Educação da Unicamp, sob orientação do professor Dario Fiorentini, e defendeu tese sobre a escrita no processo de formação contínua do professor de Matemática. De 2007 a 2009, ela compôs a coordenação do GT7 da Sociedade Brasileira de Educação Matemática (SBEM) e, em 2009, assumiu a direção do Centro de Educação a Distância (CEAD) da UFU, cargo que ocupava na época em que conversamos. Em 2014, foi promovida à classe de Professor Titular da Carreira de Magistério Superior da Universidade Federal de Uberlândia.

Apresentamos a seguir parte de sua história de vida e de formação, que compreende aproximadamente 25 anos: desde quando iniciou sua atividade docente na instituição de ensi-

itálico; ora segundo as normas técnicas para a citação de documentos, quando me refiro à sua fala presente em excertos que retirei de sua obra. 
no superior em que trabalhou durante toda a sua carreira até o momento em que concluiu o Doutorado em Educação. Destacamos que essa narrativa foi revisada pela participante, indicando concordância em participar do estudo tendo sua identidade revelada, o que foi aprovado pelo Comitê de Ética em Pesquisa em Seres Humanos da UFSCar, instituição em que a pesquisa de doutorado foi realizada.

\section{De docente do ensino superior} a formadora de professores de Matemática

Em 1980, Maria Teresa começou a trabalhar como professora na Universidade Federal de Uberlândia (UFU). 0 início de sua carreira como docente no Ensino Superior foi um tanto conturbado, devido ao acúmulo das exigências da profissão e às responsabilidades com a família. Apesar disso:

voltar à convivência com o ambiente acadêmico tornava-se cada dia mais fascinante, levandome a um envolvimento cada vez mais intenso com a profissão. Atuei em diversos cursos, entre eles: Psicologia, Ciências Biológicas, Ciências Econômicas, Pedagogia, Matemática e Administração. As diversidades inerentes aos alunos dos diferentes cursos em que atuava me faziam refletir sobre a relação de seus interesses com a Matemática e as possiveis estratégias e/ou interações que melhor atendessem às necessidades de cada contexto de trabalho. (FREITAS, 2014, p. 19)

Mesmo assim, ela seguia com as inquietações do tempo em que era aluna na Licenciatura em Matemática - "sempre me questionando, porque eu achava que eu tinha que ser diferente com os alunos. Eu não achava que aquela forma de lidar com os alunos, dura, não era aquilo que ia propiciar um processo de ensino-aprendizagem" -, uma vez que o desafio assumido quando ingressou na Licenciatura em Matemática persistia.
Penso que minha preocupação com o bem-estar do ser humano fazia com que procurasse opções para abrandar a aridez que paira na maioria dos cursos de ciências exatas. Talvez, minha inclinação para atuar em outras áreas impeliame a buscar uma adaptação possivel nas esferas em que circulava, em especial, nas relações de ensino de Matemática, que era o desafio que havia me imposto quando escolhi ser professora deste conteúdo. (FREITAS, 2006, p. 12)

As exigências da universidade e, em especial, do Departamento de Matemática, levaram-na a participar no curso de Especialização em Matemática Superior (FREITAS, 2014), oferecido na UFU por meio de um convênio com a Universidade Federal de Minas Gerais (UFMG):

"curso de especialização em matemática superior pura, da linha pura, que é hoje o mestrado da UFMG. Foi um curso muito duro e difícil, que afastou vários professores, inclusive de ir para o mestrado. Eu saí muito bem no curso, mas me questionei demais. Porque eu achava: 'Não, esse processo de estar explorando a matemática dessa forma tão dura... Não é por aí'. Então, eu me questionava, e muitas vezes".

Estudar "mais matemática" no curso de especialização não foi suficiente para Maria Teresa aplacar seus questionamentos em relação a ser professora em disciplinas com conteúdos de Matemática, nos diferentes cursos do Ensino Superior - "A imersão desmedida no estudo de disciplinas ligadas à Matemática Pura garantiu-me um excelente desempenho no curso em questão e, além disso, propiciou profundas reflexões sobre a profissão docente e o papel que estava a desempenhar" (FREITAS, 2006, p. 19-20) - e tornou mais contundentes os seus questionamentos sobre a formação inicial do professor de matemática.

Entre esses cursos, destaco a Licenciatura em Matemática, que se incumbe da formação de futuros professores de Matemática do ensino fundamental e médio. Nem sempre, os professores que nele atuavam se comprometiam com a especificidade do caráter formativo do curso, 
que parecia exigir, na interação professor-aluno, características especiais que ultrapassavam, na minha perspectiva, o conhecimento profundo do conteúdo específico. Nesse sentido, minha compreensão estava em sintonia com as idéias de Wilson et al. (1987), quando dizem que "conquanto o conhecimento pessoal do conteúdo possa ser necessário, ele não é condição suficiente para se tornar capaz de ensinar. Os professores devem encontrar maneiras de comunicar o conhecimento aos outros' (p.105). A constatação de que a profissão exige dos professores um know how que não se atém, exclusivamente, ao conhecimento do conteúdo específico da Matemática, parecia saltar-me aos olhos ao assumir simultaneamente os papéis de aluna e professora, no curso de especialização e em turmas de cursos de graduação, respectivamente. (FREITAS, 2006, p. 20)

Ela queria trabalhar com seus alunos de um modo diferente do que vivenciou - "Eu queria ser diferente. Eu queria ser diferente. Então, quando eu fazia esses trabalhos em grupos, mas com uma dinâmica diferente no grupo, de certa forma, eu queria envolvê-los. Então, eu procurava estratégias para que eles estivessem envolvidos".

Como docente da Universidade Federal de Uberlândia (UFU), tenho me dedicado a experienciar e investigar interações e mediações que melhor contribuam para o envolvimento dos alunos, nos diversos cursos em que tive oportunidade de atuar na Faculdade de Matemática. A atuação em cursos distintos, como Psicologia, Biologia, Pedagogia, Economia e Licenciatura em Matemática levou-me a perceber que a diferença de interesses e envolvimento dos estudantes em relação à Matemática relaciona-se não só ao curso em que estão inseridos, como também às suas experiências anteriores e à importância que atribuem a este conteúdo em sua formação. (FREITAS, 2006, p. 26)

Essa busca por respostas para seus questionamentos, por meios que the possibilitassem envolver seus alunos e abrandar a rigidez usualmente associada ao ensino da Matemáti- ca, levou Maria Teresa ao encontro do National Council of Teachers of Mathematics (NCTM ${ }^{11}$ ).

"Mas nesses questionamentos todos, eu tenho que te falar que eu queria mais. E eu comecei então a fazer as leituras do NCTM, me aproximar do NCTM, comecei a ir em alguns eventos e teve uma época que eu me afiliei ao NCTM. Comecei a ir nos eventos, nos principais, os anuais. Eu fui em vários e comecei a oferecer oficina lá, que eram os workshops de 80 minutos. Então, eu mandava os trabalhos de oficina, minicurso, com professores de lá, com as dinâmicas que eu desenvolvia aqui com os alunos da licenciatura. Então, eu trabalhava lá e via que a realidade de lá não era muito diferente das nossas. A vibração daqueles professores não era diferente".

O contato com a escola e com os professores brasileiros, que lhe permitia estabelecer comparação com o contexto norte-americano, resultou da sua associação a outros docentes:

um grupo de professores do Departamento de Matemática da Universidade Federal de Uberlândia (UFU), no qual estamos incluídos, manteve-se, desde os meados dos anos 80 , participante do processo de consolidação de uma área da Matemática ou da Educação, que tivesse como preocupação maior o ensino da Matemática e suas implicações no âmbito da formação de um cidadão que, não necessariamente, se dedicaria ao estudo da Matemática como fim último. Essa área não estava, na época, muita bem delineada para o grupo como da Matemática ou da Educação, por apresentar interesses multidisciplinares. Foi, entretanto, logo reconhecida como Educação Matemática. (FREITAS, 2000, p. 7)

Segundo Freitas (2000), os professores que compunham esse grupo trabalhavam com atividades relacionadas à prática de ensino, mantendo com a escola um contato que thes possibilitava conhecer as dificuldades de professores e de estagiários, quanto ao ensinar e ao aprender matemática. Posteriormente, esses docentes passaram a ser solicitados para

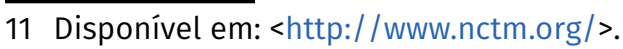


procurar sanar as dificuldades encontradas pelos professores e para sugerir uma metodologia considerada mais condizente com cada situação.

Foi por meio da participação nesse grupo que ela começou a trabalhar em atividades relacionadas com a formação de professores "nosso envolvimento com formação de professores e estágio supervisionado inicia-se por meio de trocas entre os colegas de trabalho com maior experiência profissional, no intuito de auxiliá-los nas atividades inerentes à disciplina Prática de Ensino" (FREITAS, 2000, p. 9).

“Eu tinha muito curso de extensão e eu estava o tempo inteiro na formação continuada de professores. Eu estava muito próxima, dentro de escola, dos professores. Eu queria ouvir os professores e estar com eles. Porque, quando eu estava lá na UFU ainda, eu fiquei coordenando o Laboratório de Ensino de Matemática, o grupo GAAEM, que é Grupo de Apoio a Atividades de Ensino da Matemática, que tinha projetos de extensão. Então, eu fiquei muito tempo envolvida com o Laboratório de Ensino, produção de material e os professores da rede, trazendo os professores para conhecer a universidade e os alunos também, que iam pleitear, entrar em algum curso".

A proximidade com as demandas escolares, na Licenciatura em Matemática e na formação continuada de professores de Matemática, fez com que ela recorresse de forma mais intensa ao conhecimento produzido no campo da Educação Matemática.

Nessa ocasião, assumimos a coordenação do LEMAT e a disciplina Prática de Ensino de Matemática I, tendo, a partir de então, aumentado nossa atenção para as publicações nacionais $\mathrm{e}$ internacionais da área de Educação Matemática, intensificando nossa participação em eventos da área, culminando, em 1995, com nossa filiação ao National Council of Teacher of Mathematics NCTM, na busca de ampliar o acesso às publicações internacionais da área que viessem acrescentar-se às publicações nacionais e da Sociedade Brasileira de Educação Matemática, sendo que, a nossa filiação havia se dado no início de sua criação. (FREITAS, 2000, p. 13-14)

Ao assumir a Prática de Ensino de Matemática I, Maria Teresa ficou também responsável pelo estágio supervisionado que, na época, estava associado à carga horária dessa disciplina. A aproximação da realidade escolar, proporcionada pela convivência e pelo acompanhamento dos estagiários da Licenciatura em Matemática, lhe possibilitou identificar a importância de aproximar também o futuro professor do contexto escolar.

Percebemos, cada vez mais, que a aproximação dos alunos/futuros professores de seu campo de trabalho e dos professores das escolas, que são os profissionais atuantes em seu campo de interesse, favorecia excelentes oportunidades de trocas importantes para a consolidação, formação e produção de saberes na maioria das vezes desapercebidos. Por diversos momentos, incluímos os estagiários, alunos da disciplina Prática de Ensino de Matemática, como monitores em projetos de extensão, no intuito de propiciar uma maior convivência e reflexão junto aos professores das escolas da comunidade e região. (FREITAS, 2000, p. 14-15)

Maria Teresa passou a conceber o estágio sob uma ótica extensionista e buscou desenvolver um trabalho que fosse permeado pelo diálogo e pela troca de saberes entre os elementos envolvidos, em uma via de mão dupla, entre universidade e sociedade (FREITAS, 2000). Essa visão a motivou a investigar "as relações e trocas por meio das quais se constroem e produzem intervenções e ações que contribuem tanto para a formação do futuro profissional, como para os profissionais em serviço" (FREITAS, 2000, p. iv) na pesquisa que desenvolveu no Mestrado em Educação.

"E quando eu fiz o mestrado na educação, eu já estava trabalhando com estágio supervisionado. Então, eu vi essa perspectiva do estágio numa perspectiva extensionista, a extensão 
como ela é percebida hoje. Porque não é aquilo que você leva pronto, mas aquilo que você vai na comunidade ver o que é necessário, o que eles estão precisando, para você, nesse diálogo, estar estabelecendo um projeto. Então, O Estágio Supervisionado na Perspectiva Extensionista, foi o meu tema de mestrado. E aí, fiz uma leitura dos fóruns de pró-reitores de extensão, de como era compreendida a extensão e também aliado a como eu compreendia o estágio e toda a literatura do estágio no processo de formação de professores. E tinha muito a ver com a formação de extensão, com formação continuada, porque eu sempre trabalhei a vida inteira com formação continuada de professores".

Com a investigação apresentada em sua dissertação (FREITAS, 2000), mostrou que o estágio, se desenvolvido como trabalho coletivo:

possibilita o desencadeamento da prática pedagógica, levando a um repensar de seus objetivos e das suas ações. Nesse processo, com os alunos, professores e escola, cria-se um espaço social de participação coletiva e política. Justamente aqui, o 'saber' síntese então produzido, construído à medida que o grupo em interação articula o saber local e $o$ acadêmico, abre perspectivas de um novo conhecimento. Inicia-se, portanto, um processo vivo, e a Universidade se engaja numa ação social efetiva. (FREITAS, 2000, p. 131)

Depois de concluir o mestrado, continuou participando de eventos acadêmicos, nacionais e internacionais, como os do NCTM:

"Depois que eu fiz o mestrado, continuei com essas minhas andanças. E as minhas andanças pelos congressos lá fora sempre aconteceram. Em uma dessas idas para o NCTM, quando eu volto, eu recebo o convite para publicar naquela revista Mathematics Teachers: 'Não guarde o seu material ainda. A quantidade de professores que estiveram presentes no seu workshop foi pequena em relação à quantidade que podia aproveitar'".

Esse texto não foi escrito, pois, nessa época, ela se dedicou a pleitear uma vaga no dou- torado - "uma coisa que eu arrependo, é não ter escrito com esse material que estava todo comigo, escrito em inglês, e eu não escrevi para o Mathematics Teachers. Eu tenho o convite, mas não tenho essa publicação".

Foi aprovada no processo seletivo do Programa de Pós-Graduação em Educação da Unicamp, mudou-se para Campinas e iniciou o doutorado no ano 2002, sob orientação do professor Dario Fiorentini. Disse que foi "muito bem acolhida pelo grupo, pelos professores, pelo espaço todo: lá conheci Cármen, Adair, Diana e todos". "A receptividade e o calor humano dos professores e dos colegas nesta nova empreitada forneceram-me um ânimo diferente e uma maneira especial de ver o mundo e a vida" (FREITAS, 2006, p. 6).

Para Maria Teresa, o doutorado foi um autêntico momento formativo, de constante busca para assumir a posição de pesquisadora:

Foram momentos de muito prazer e alegria que tive o privilégio de viver em companhia de pessoas da academia que me ensinam a discordar, concordar, duvidar, emitir opinião, ser autêntica, mediar discussões, encontrar objetivos, elaborar questões, ter rigor acadêmico e, acima de tudo, priorizar a seriedade, a responsabilidade e a moral. Vale novamente aqui relembrar que eu me dei este privilégio por me permitir a oportunidade de viver a academia. (FREITAS, 2009, p. 104)

Ela destacou a relevância de estar "atenta, desde o início dessa caminhada formativa, à riqueza e à importância de viver os espaços do ambiente universitário e usufruir das relações com as pessoas que ali circulam" (FREITAS, 2009, p. 103).

“Então, eu tinha um pé no IMEC,12 um pé na Faculdade de Educação e um pé na faculdade também de Letras, porque eu fiz disciplinas por conta da escrita lá também. Então, eu tive um círculo de amizades de alunos desses diferen-

12 Instituto de Matemática, Estatística e Computação Científica da Unicamp. 
tes espaços, o que foi muito interessante. Com certeza, e eu falava sempre para o Dario, todos os espaços são muito formativos. E o aluno que não vai vivenciar o doutorado na universidade, ele está perdendo. Ele está perdendo essa convivência de outros espaços. Até mesmo o espaço onde você está jantando ou conversando com os professores".

Reforçou o entusiasmo com que vivenciou essa etapa de sua vida - "então, fiquei muito entusiasmada com o doutorado, com essas pessoas que contribuíram muito para minha formação" - e destacou a importância de ter trabalhado com a escrita em sua tese - "sempre com esse foco, o foco da escrita já vem comigo o tempo todo. Desde os diários. E eu sempre quis que isso acontecesse".

Meus caminhos, em diferentes momentos, trouxeram a escrita como um ponto marcante de minha história, mostrando-me sua potencialidade para aguçar o poder de reflexão, reorganização de idéias e tomada de decisões, contribuindo de maneira efetiva para o meu desenvolvimento pessoal e profissional. Este percurso tornou-me sensivel e motivada a investigar as potencialidades educativas da escrita para o professor de Matemática, sobretudo em seu desenvolvimento profissional. (FREITAS, 2006, p. 22)

Assumir "a importância da escrita não diretamente relacionada a símbolos e fórmulas, no processo de ensino e aprendizagem da Matemática nos cursos de formação inicial de professores, significa romper com a tradição pedagógica ainda vigente na maioria dos cursos de licenciatura" (FREITAS, 2006, p. 81-82). Por essa razão, ela tomou as aulas de uma professora interessada em vivenciar uma prática de ensino de Matemática que contemplasse a interação de diferentes formas de comunicação escrita associadas ao conteúdo específico de Matemática como cenário de sua pesquisa no doutorado:

quando me vejo entre os alunos do Curso de Licenciatura de Matemática da Unicamp, ob- servando criteriosamente alguns dos momentos vivenciados por eles numa disciplina de conteúdo específico, mas que agrega outras preocupações e estratégias que não apenas a habilidade de lidar com o objeto de estudo em questão, percebo um constante movimento de ida e vinda à nossa formação e atuação profissional. Essa minha inquietação se justifica por estar em estado de alerta: procuro entender e identificar aqueles momentos que mostram caminhos catalisadores de elementos essenciais para a formação de um professor de Matemática capaz de reconhecer a importância do conteúdo, mas que também considere a compreensão do significado em sobreposição à capacidade de lidar aleatoriamente com um amontoado de fórmulas e símbolos aparentemente com pouco ou nenhum significado para muitos alunos. (FREITAS, 2006, p. 16)

Para Maria Teresa, a formação desse professor de matemática - capaz de reconhecer a importância do conteúdo matemático, considerando a compreensão do significado por parte do aluno - está associada à relação que o formador deve estabelecer entre o conteúdo matemático em estudo e as formas de abordá - lo em cada uma das disciplinas na Licenciatura em Matemática.

"Eu tenho uma coisa que me incomoda muito quando se fala em disciplina específica e disciplina pedagógica no curso de licenciatura. Isso, para mim, não existe. Todas as disciplinas, na licenciatura, deveriam ou devem ter um cunho pedagógico. Porque é ali que você vai fazer o aluno vivenciar uma dinâmica diferente com o conteúdo específico junto. Que foi o que fiz na minha tese. E aí, eu vejo, quando a pessoa fala: “Não, mas o meu trabalho é com conteúdo específico. Não tem nada a ver". Não! Tem tudo a ver. Porque o aluno se forma em todos esses espaços. Você tem esses exemplos que você vai absorvendo. Você vai reproduzindo coisas que você viveu. E você começa a ter confiança ou não, se você vivenciou aquilo. Então, se você trabalhou com Geogebra, você vai, depois, com mais confiança trabalhar com seus alunos. Se você nunca viu ou só ficou sabendo por teoria, você não vai fazer isso. Se você fala que um jogo 
dá um resultado e deve ser trabalhado dessa ou daquela forma, então, muito bem, você leu, está na teoria. Mas se você não vivenciou e sentiu na pele o que é aquele processo, você não vai conseguir ter confiança para trabalhar depois naquilo com seus alunos. Então, eu sempre acreditei nisso e tentei colocar isso em prática".

Tentar colocar em prática o que acreditava levou Maria Teresa de professora iniciante no Ensino Superior - preocupada em atender as necessidades de cada contexto em que atuava, questionadora da formação do professor de Matemática - a formadora de professores de matemática, em constante contato com a escola, consciente de que a profissão docente exige mais do que conhecimento do conteúdo a ensinar, tendo atingido a posição almejada de pesquisadora, concretizada com a realização do mestrado e do doutorado - "uma formação para lapidar a pesquisadora que acreditei estar inerente ao meu ser professora" (FREITAS, 2014, p. 25).

\section{Considerações sobre as}

\section{experiências de desenvolvimento profissional de Maria Teresa}

Com a premissa de que "a experiência modifica quem a faz e por ela passa" (Dewey, 1971, p. 26), ao compor a narrativa apresentada, identificamos experiências que entendemos terem influenciado o desenvolvimento profissional de Maria Teresa, ou seja, aquelas em que a formadora se transformou, que foram: relação de proximidade e interação com a escola e com o professor que ensina Matemática na Educação Básica; a identificação/distinção de uma matemática particular para o trabalho do professor; a valorização de um conhecimento matemático para a formação do professor que ensina Matemática, a ser abordado com os outros da Base de Conhecimentos para o Ensino; a constituição de uma prática na formação orientada para a atuação profissional do professor que ensina Matemática; e a busca de sustentação teórica e empírica para compreender e orientar sua atuação profissional.

Desse modo, ter uma relação de proximidade e interação com a escola e com o professor que ensina Matemática na Educação Básica, mantendo com a escola um contato que lhe possibilitava conhecer as dificuldades de professores e de estagiários quanto ao ensinar e ao aprender matemática (FREITAS, 2000) - "eu estava o tempo inteiro na formação continuada de professores. Eu estava muito próxima, dentro de escola, dos professores. Eu queria ouvir os professores e estar com eles" - contribuiu, por exemplo, para que Maria Teresa passasse a conceber o estágio sob uma ótica extensionista, desenvolvendo um trabalho, na Licenciatura em Matemática, que fosse permeado pelo diálogo e pela troca de saberes entre os elementos envolvidos, em uma via de mão dupla entre universidade e sociedade (FREITAS, 2000).

Essa interlocução com a escola, assim como suas vivências como estudante e professora de Matemática, possibilitou-lhe outra experiência: a identificação/distinção de uma matemática particular para o trabalho do professor. Por considerar que "a profissão exige dos professores um know-how que não se atém, exclusivamente, ao conhecimento do conteúdo específico da Matemática" (FREITAS, 2006, p. 20), ela entende que o professor de Matemática deve ser "capaz de reconhecer a importância do conteúdo, mas que também considere a compreensão do significado em sobreposição à capacidade de lidar aleatoriamente com um amontoado de fórmulas e símbolos aparentemente com pouco ou nenhum significado para muitos alunos" (FREITAS, 2006, p. 16).

Experiência que se prolonga na valorização de um conhecimento matemático para a formação do professor que ensina Matemática, 
a ser abordado com os outros da Base de Conhecimentos para o Ensino, o que se pode ver quando ela faz referência às disciplinas da Licenciatura em Matemática - "Todas as disciplinas, na licenciatura, deveriam ou devem ter um cunho pedagógico. Porque é ali que você vai fazer o aluno vivenciar uma dinâmica diferente com o conteúdo específico junto" - ou quando destaca a especificidade do caráter formativo desse curso, que parecia exigir, na interação professor-aluno, características especiais que ultrapassavam, em sua perspectiva, o conhecimento profundo do conteúdo específico (FREITAS, 2006).

Esse posicionamento provavelmente contribuiu para que ela mostrasse, em sua história de vida, a constituição de uma prática na formação orientada para a atuação profissional do professor que ensina Matemática, ao viabilizar a aproximação dos futuros professores de seu campo de trabalho e dos professores da escola, o que "favorecia excelentes oportunidades de trocas importantes para a consolidação, formação e produção de saberes na maioria das vezes desapercebidos" (FREITAS, 2000, p. 14-15), ou ao proporcionar aos licenciandos vivências que lhes conferissem mais confiança para atuar como professores de Matemática:

"Você vai reproduzindo coisas que você viveu. E você começa a ter confiança ou não, se você vivenciou aquilo. Então, se você trabalhou com Geogebra, você vai, depois, com mais confiança trabalhar com seus alunos. Se você nunca viu ou só ficou sabendo por teoria, você não vai fazer isso. Se você fala que um jogo dá um resultado e deve ser trabalhado dessa ou daquela forma, então, muito bem, você leu, está na teoria. Mas se você não vivenciou e sentiu na pele o que é aquele processo, você não vai conseguir ter confiança para trabalhar depois naquilo com seus alunos".

Para viabilizar práticas de formação como essas, Maria Teresa mostra uma constante busca de sustentação teórica e empírica para compreender e orientar sua atuação profissional, tal como se pode ver na atenção que dedicava às publicações nacionais e internacionais da área de Educação Matemática, na sua participação em eventos da área, na filiação ao NCTM e à Sbem, e na realização das pesquisas de mestrado e de doutorado. Essa busca por experienciar e investigar interações e mediações que melhor contribuam para o envolvimento dos alunos, nos diversos cursos em que teve oportunidade de atuar (FREITAS, 2006) possibilitou a ela perceber: "a diferença de interesses e envolvimento dos estudantes em relação à Matemática" (FREITAS, 2006), o saber síntese produzido em um estágio supervisionado desenvolvido na perspectiva extencionista (FREITAS, 2000), as rupturas com a tradição pedagógica ainda vigente na maioria dos cursos de licenciatura (FREITAS, 2006), por exemplo.

Entendemos essas experiências de desenvolvimento profissional como vias de transformação pessoal, pois, por meio delas e para elas, Maria Teresa foi constituindo outras formas de estar na formação de professores, as quais the proporcionaram produzir conhecimentos que fundamentam e orientam suas ações e suas práticas, contribuindo para a constituição de uma profissionalidade. Essas experiências de desenvolvimento profissional vivem e se prolongam em experiências sucessivas, pois foi a formadora transformada que se modifica nas experiências seguintes, quando a ação de quem passa pela experiência muda de algum modo as condições objetivas nas quais as experiências se passam (DEWEY, 1971).

\section{À guisa de conclusão}

Entender o desenvolvimento profissional do modo como fizemos, contemplando, além do processo, a pessoa que se desenvolve ao longo do tempo nos contextos em que atua, gerou a 
necessidade de atingir o caráter subjetivo do desenvolvimento profissional e o processo por meio do qual a pessoa se desenvolve, destacando a importância do sujeito tocado pela experiência, que por ela se deixa alcançar, formar e transformar (COURA, 2018).

Com a premissa de que "a experiência modifica quem a faz e por ela passa" (Dewey, 1971, p. 26), ao compor a narrativa apresentada neste artigo, identificamos experiências que entendemos terem influenciado o desenvolvimento profissional de Mara Teresa, ou seja, aquelas em que a formadora se transformou. Para alcançar em alguma medida os aspectos que destacamos do desenvolvimento profissional da formadora e o caráter transformador das suas experiências, as narrativas se mostraram como vias sem as quais não conseguiríamos construir as considerações aqui registradas. Além de integrar a biografia da participante ao estudo, a narrativa possibilitou atender a necessidade de abordar os respectivos processos de desenvolvimento diacronicamente, levando em consideração a história da formadora, as relações que estabeleceu com suas vivências, o momento atual e o movimento de suas expectativas futuras. Com o recurso da narrativa, também foi possivel contemplar alguns dos contextos em que ela se inseriu, onde viveu e onde trabalhou, ao longo de um determinado período que, no nosso artigo, compreende os 25 anos passados desde quando ela começou a atuar como docente no Ensino Superior até a conclusão do Doutorado em Educação.

Contar as experiências de desenvolvimento profissional no espaço tridimensional da pesquisa narrativa (Clandinin; Connelly, 2011), abordando a temporalidade dos acontecimentos, suas condições pessoais e sociais e o contexto (tempo e espaço) em que ocorreram, foi fundamental para compreender como Maria Teresa se desenvolveu profissionalmente. Como procuramos mostrar, a narrativa, por ter permitido representar um conjunto de dimensões da experiência que a investigação formal não contempla, foi a forma de compreender as experiências de desenvolvimento profissional de uma formadora de professores de Matemática, pois tornou possivel atingir o caráter subjetivo do desenvolvimento profissional e o processo por meio do qual a pessoa se desenvolve, destacando a importância do sujeito tocado pela experiência, e que por ela se deixa alcançar, formar e transformar.

\section{Referências}

Altet, M.; Paquay, L.; Perrenoud, P. A profissionalização dos formadores de professores. Porto Alegre: Artmed, 2003.

AndrÉ, M. E. D. A. et al. O trabalho docente do professor formador no contexto atual das reformas $e$ das mudanças no mundo contemporâneo. Revista Brasileira de Estudos Pedagógicos, Brasília, v. 91, n. 227, p. 122-143, jan./abr. 2010.

AndrÉ, M. E. D. A. et al. O papel do professor formador e das práticas de licenciatura sob o olhar avaliativo dos futuros professores. Revista Portuguesa de Investigação Educacional, Porto, v. 12, p. 101-123, 2012.

BOLIVAR, A.; DOMINGO, J.; FERNÁNDEZ, M. La investigación biográfico-narrativa en educación: enfoque y metodologia. Madri: La Muralla, 2001.

CLANDININ, D. J.; CONNELLY, F. M. Pesquisa narrativa: experiência e história em pesquisa qualitativa. Tradução do Grupo de Pesquisa Narrativa e Educação de Professores ILEEI/UFU. Uberlândia, MG: EDUFU, 2011.

COCHRAN-SMITH, M. Teacher educators as researchers: multiple perspectives. Teaching and Teacher Education: An International Journal of Research and Studies, Orlando, v. 21, n. 2, p. 219-225, fev. 2005.

COCHRAN-SMITH, M.; LYTLE, S. L. Relationships of knowledge and practice: Teacher learning in communities. Review of Research in Education, Washington, v. 24, p. 249-305, 1999. 
CONTRERAS DOMINGO, J. Relatos de experiencia, en busca de un saber pedagógico. Revista Brasileira de Pesquisa (Auto)Biográfica, Salvador, v. 1, n. 1, p. 14-30, jan./abr. 2016.

COSTA, V. G.; PASSOS, L. F. O professor formador e os desafios da formação inicial de professores de matemática. Educação Matemática Pesquisa, São Paulo, v. 11, n. 3, p. 597-623, 2009.

COURA, F. C. F. O impacto da prática pedagógica dos formadores de professores na formação dos licenciandos em matemática. Paidéia - Universidade FUMEC, Belo Horizonte, n. 14, p. 55-70, jan./jun. 2013.

COURA, F. C. F. Desenvolvimento profissional de formadores de professores de Matemática que são investigadores da docência. 2018. 262f. Tese (Doutorado em Educação) - Universidade Federal de São Carlos, São Carlos. 2018.

COURA, F. C. F; PASSOS, C. L. B. Estado do conhecimento sobre o formador de professores de Matemática no Brasil. Zetetiké (on-line), v. 25, p. 7, 2017.

COURA, F. C. F; PASSOS, C. L. B. Desenvolvimento profissional de formadoras de professores de Matemática que são investigadoras da docência: de estudante a professora. In: SEMINÁRIO INTERNACIONAL DE PESQUISA EM EDUCAÇÃO MATEMÁTICA, 7., 2018, Foz do Iguaçu. Anais... Brasília, DF: Sbem, 2018. p. 1-12.

Dal-Forno, J. P.; Reali, A. M. M. R. Formação de formadores: delineando um programa de desenvolvimento profissional da docência via internet. Revista Profissão Docente, Uberaba, MG, v. 9, n. 20, p. 75-99, jan./jul. 2009.

Dewey, John. Experiência e educação. Companhia Editora Nacional: São Paulo, 1971.

DOMINGO SEGOVIA, J. Teoria fundamentada del professorado desde um enfoque biográfico-narrativo. Fundamentación, processos e herramientas. In: ABRAHÃO, M. H. M. B.; BOTÍA, A. B. (Orgs.). La investigación (auto)biográfica en educación: miradas cruzadas entre Brasil y España. Granada: Editorial Universidad de Granada, 2014. p. 110-141.

FIORENTINI, D. A investigação em educação matemática sob a perspectiva dos formadores de professo- res. In: SEMINÁRIO DE INVESTIGAÇÃO EM EDUCAÇÃO MATEMÁTICA, 15., 2004, Covilhã, Portugal. Actas. ... Lisboa: Sociedade Portuguesa de Ciências da Educação - Secção de Educação Matemática, 2004. p. 31-67.

Fiorentini, D. et al. Formação de professores que ensinam Matemática: um balanço de 25 anos da pesquisa brasileira. Educação em Revista, Belo Horizonte, n. 36, p. 137-160, dez. 2002.

FIORENTINI, D.; Oliveira, A. T. C. C. O lugar das matemáticas na licenciatura em matemática: que matemáticas, que práticas formativas? Bolema - Boletim de Educação Matemática, Rio Claro, v. 27, n. 47, p. 917-938, 2013.

FREITAS, M. T. M. Estágio curricular em matemática na perspectiva de extensão universitária: estudo de uma experiência na UFU. 2000. 168 f. Dissertação (Mestrado em Educação) - Programa de Pósgraduação em Educação, Universidade Federal de Uberlândia, Uberlândia, 2000.

FREITAS, M. T. M. A escrita no processo de formação contínua do professor de matemática. 2006. $300 \mathrm{f}$. Tese (Doutorado em Educação) - Faculdade de Educação, Universidade Estadual de Campinas, Campinas, 2006.

FREITAS, M. T. M. Escritas e leituras: os bastidores da participação em um programa de doutoramento em Educação Matemática. In: LOPES, C. E.; NACARATO, A. M. (Orgs.). Educação matemática, leitura e escrita: armadilhas, utopias e realidade. Campinas, SP: Mercado de Letras, 2009. p. 101-111.

FREITAS, M. T. M. Memorial: a arte de tecer o próprio caminho. Memorial (Memorial apresentado como exigência parcial para promoção na carreira da Classe de Professor Associado IV para a Classe de Professor Titular da Carreira de Magistério Superior da Universidade Federal de Uberlândia) - Universidade Federal de Uberlândia, 2014. Não publicado.

GARNICA, V. Notas sobre narrativa e Educação Matemática. In: LOPES, C. E.; NACARATO, A. N. (Orgs.). Educação matemática, leitura e escrita: armadilhas, utopias e realidade. Campinas, SP: Mercado de Letras, 2009.

Guimarães, M. F. A fidelidade à origem: o desenvolvimento profissional de uma professora de mate- 
mática. Lisboa: Colibri, 2005.

LARROSA BONDÍA, J. Notas sobre a experiência e o saber de experiência. Revista Brasileira de Educação, Rio de Janeiro, n. 19, p. 20-28, abr. 2002.

Hobold, M. S.; MENSLIN, M. S. A implicação do trabalho do formador na constituição da profissionalidade dos licenciandos. Revista Diálogo Educacional, Curitiba, v. 12, n. 37, p. 783-801, set./dez. 2012.

KELCHTERMANS, G.; SMITH; K.; VANDERLINDE, R. Towards an 'international forum for teacher educator development': an agenda for research and action. European Journal of Teacher Education, v. 41, n. 1, p. 1-14, 2018. Disponível em: <http:/ / www.tandfonline. com/doi/full/10.1080/02619768.2017.1372743>. Acesso em: 18 set. 2017.

Marcelo García, C. La formación de los formadores como espacio de trabajo e investigación: dos ejemplos. XXI Revista de Educación, Huelva, n. 1, p. 33-57, 1999a.

MARCELO GARCÍA, C. Formação de professores. Para uma mudança educativa. Porto: Porto Editora, 1999b.

MINGORANCE DÍAZ, P. Aprendizaje y desarrollo profesional de los profesores. In: MARCELO GARCÍA, C. (Org.). La función docente. Madrid: Editorial Síntesis, 2001. p. 85-102.

MIZUKAMI, M. G. N. Aprendizagem da docência: conhecimento específico, contextos e práticas pedagógicas. In: NACARATO, A. M.; PAIVA, M. A. V. A. (Orgs.). A formação do professor que ensina matemática: perspectivas e pesquisa. Belo Horizonte: Autêntica, 2006. p. 213-231.

MIZUKAMI, M. G. N. Formadores de professores, conhecimentos da docência e casos de ensino. In: REALI, A. M. de M. R.; MIZUKAMI, M. G. N. (Orgs.). For- mação de professores: práticas pedagógicas e escola. São Carlos: EDUFSCAR, 2010. p. 151-174.

PASSOS, c. l. b. et al. Desenvolvimento profissional do professor que ensina Matemática: uma meta-análise de estudos brasileiros. Quadrante - Revista Teórica e de Investigação - APM, Lisboa, v. 15, n. 1-2, p. 193-219, jan./jun. 2006.

PASSOS, L. F. O trabalho do professor formador e o contexto institucional: desafios e contribuições para o debate. Educação \& Linguagem, São Paulo, n. 15, p. 99-116, jan./jun. 2007.

PASSOS, L. F.; SILVA, S. R. L. S.; FERREIRA, V. L. Desenvolvimento profissional e práticas dos formadores: as vozes entrecruzadas dos licenciandos e dos formadores dos cursos de Licenciatura em Matemática. In: ENCONTRO NACIONAL DE EDUCAÇÃO MATEMÁTICA - ENEM, 11., 2013, Curitiba. Anais... Curitiba: Editora da PUCPR, 2013. p. 1-12.

SANTOS, V. M. A formação de formadores: que formação é essa? Revista de Educação PUC-Campinas, Campinas, n. 18, p. 61-64, jun. 2005.

Vaillant, D. Formación de formadores. Estado de la práctica. Buenos Aires: Preal, 2003.

VANASSCHE, E.; KELCHTERMANS, G. Teacher educators' professionalism in practice: Positioning theory and personal interpretative framework. Teaching and Teacher Education: An International Journal of Research and Studies, Orlando, v. 44, p. 117-127, 2014.

ZEICHNER, K. Becoming a teacher educator: a personal perspective. Teaching and Teacher Education: An International Journal of Research and Studies, Orlando, v. 21, n. 2, p. 117-124, 2005.

Recebido em: 10.01.2019. Aprovado em: 26.03.2019

Flávia Cristina Figueiredo Coura é Doutora em Educação, pela Universidade Federal de São Carlos. Professora da Universidade Federal de São João Del Rei - UFSJ - Professor Adjunto II - na área de Educação Matemática, com enfoque nos temas da formação do professor que ensina Matemática, do ensino-aprendizagem em Matemática na Educação Básica e da escrita matemática. É integrante do Grupo de Estudos e Pesquisas em Educação Matemática (GEM-UFSCar). e-mail: flaviacoura@ufsj.edu.br 